\title{
DOI: 10.7596/taksad.v8i3.2021
}

Citation: Herdova, T., \& Mitlytska, V. (2019). Features of Dramaturgy of Ptushkin's Piano Suite "Theater Kaleidoscope". Journal of History Culture and Art Research, 8(3), 306-316. doi: http://dx.doi.org/10.7596/taksad.v8i3.2021

\section{Features of Dramaturgy of Ptushkin's Piano Suite "Theater Kaleidoscope"}

\author{
Tetiana Herdova ${ }^{1}$, Viktoriia Mitlytska²
}

\begin{abstract}
The problems of the art wholeness of musical composition are actual for both composer's and performer's creative work. The article suggests the study of V. Ptushkin's "Theater Kaleidoscope" piano suite, its drama peculiarities as one of the possible variants of the problem solution. Genrehistorical ties and music-genre panorama of the Ptushkin's cycle are analyzed in the article. The drama suite features in the author's application of everyday life dances are described in this publication. The Waltz peculiarities as genre basis drama in the third cycle part are analyzed. The role of two types of drama in the formation of the artistic integrity of the suite is studied on reasonable and objective criteria. The novelty of the suggested problem is in the definition of its genre-historical ties with the ancient chamber suite and with the commedia dell'arte. It also involves the value of a dramatic suite type as the main organizing principle of the entire cycle. The "event", lyric-dramatic type of the dramaturgy in the third suite part is based. The connection of the inner dramaturgy of the third part and the structural organization of the artistic wholeness are determined. This is the basis of the ternary in the entire cycle. The role of the fourth part as the final and the original reprise returning of the drama suite type are noted.
\end{abstract}

Keywords: Theatrical, Carnival, Suite cycle, Piano, Dramaturgy.

\footnotetext{
1 Ph.D. in Arts Study, Senior Lecturer in the Actor Skill Department, Zaporizhzhia National University, Ukraine. E-mail: gerdova77806@gmail.com

2 Ph.D. in Arts Study, Associate Professor of the Instrumental Performance, Music Art Department, Bogdan Khmelnitsky Melitopol State Pedagogical University, Ukraine. E-mail: viktoriamitlitska@gmail.com
} 


\section{Introduction}

The artistic wholeness organization of musical composition is always actual and eternal while there exists a composer's creative work and the creative work of a performer (musician, actor). Its solution can be both multiple and individual. In any case, a composition (either musical or stage) will be an organized embodiment of the author's artistic idea ${ }^{3}$. Since a characteristic feature of an artistic work (composition) is an organization, then the organization problem of an artistic wholeness remains eternally actual. It is actual not only in the artistic creativity practical aspect but in a theoretical one.

As an object of musicological research work, an artistic wholeness can be represented by various aspects of the study. The drama of musical composition is one of them. The actuality of the study of the artistic wholeness organization problem also requires its drama examination, because they are interconnected as an object and a subject. Study of an artistic wholeness in Ptushkin's suite ${ }^{4}$ is also necessary as he is a contemporary representative of the classical Ukrainian music.

The aim of the article is to expose drama peculiarities of the piano suite of Ptushkin "Theater Kaleidoscope". The tasks are:

1. To expose genre-historical links and musical-genre panorama of the cycle "Theater Kaleidoscope";

2. To reveal features of suite drama in the author's use of folk dancing genres;

3. To analyze special features of waltz as drama genre basis in the third part of the cycle and its role in the formation of the wholeness;

4. To ground form formation of two dramaturgy types in the cycle.

\section{Literature Review}

The problem raised in the article lies on the crossroads of musical composition organization problems (including the problems of conception apparatus, terminology, performance manifestation and so on) and the tasks of Ukrainian contemporary study of musical art. Taking into account the above mentioned, the publications of the problem can be grouped into two parts. The first one includes fundamental musicology examination of musical creative work regularities and organization problems of musical work art wholeness.

\footnotetext{
3 "Everything accidental is hostile to an artist. Art represents an absolute opposition to the chaos, which appears as a consequence of irregular piling up of numerous coincidences. Any art presupposes a preliminary conception" (Kreg, 1988, p. 213).

${ }^{4}$ Vladimir Mikhaylovich Ptushkin - People's Artist of Ukraine, Award Winner Municipal Prize of I. Sletin, B. Lyatoshinsky Republican Prize Winner, All Ukrainian V. Kosenko contest winner, International composer's contest winner, devoted to the 300 anniversary of St. Petersburg, professor of composition and instrumentation chair of Kharkov National Art University (2004), Head of the department.
} 
Fundamental analysis of universal problems is not represented in musicology research works. That is why researches of preceding years are also vital today. The works of Bobrovsky $(1971,1978)$, Chernova (1984), Livanova (1980), Nazaykinsky (1982), Ruchievskaya (1977), Skrebkov (1973), Sollertinsky (1963) are used as researches representing a basis of theoretical and practical study of Ptushkin's suite organization.

Chernova's (1984) research raised the problem of drama concept interpretation applied to the analyses of Ptushkin's suite "Theater Kaleidoscope". Sollertinsky's (1963) work became the basis of the drama type definition of one of the parts of Ptushkin's cycle; Skrebkov's (1973) understanding of drama type gave an opportunity to look at the process-pattern suite organization of "Theater Kaleidoscope" in the light of theme development. Ruchievskaya's (1977) study of music theme functions and the problems of correlation and interaction of emotion-image motion within the wholeness and the closed composition of the wholeness of Livanova's research (1980) made it possible to distinguish various drama types used in Ptushkin's work. Ideas of Livanova (1980), Ruchievskaya (1977) and Skrebkov (1973) stimulated the application of holistic music analysis when studying peculiarities of suite drama of Ptushkin's suite “Theater Kaleidoscope”. Bobrovsky's $(1971,1978)$ and Nazaykinsky's $(1982)$ works stimulated defining functions of suite parts in the artistic wholeness as well it helped to come to the conclusion about a ternary form within the cycle as the pattern of the background.

The second group of scientific publications - research works of Ptushkin's creative work includes a limited number of works, in which composer's piano compositions are not the subject of the study. A review of some composers' style questions is determined by Bobina (2001). Performing aspect of the Ptushkin's cycle compositions became the object of the study for Inutochkina (1996). However, questions of dramaturgy and the unity of art wholeness of the music composition in Ptushkin's creative work are not examined yet. The examination of these questions in the Ptushkin's piano suite is based on the conceptual foundations of the performer's art described by Diatlov (2014) and Vartanov (2012).

\section{Discussion}

Ptushkin's suite "Theater Kaleidoscope" represents a cycle consisting of four parts. The first one - "Masks"; the second one - "Divertissement"; the third one - "Waltz"; the fourth one - "Gallop". The cycle is marked by dualism, consisting of the unity of theatrical nature and musical means of its expression.

On the one hand, the name of the whole cycle expresses theater nature of the composition and appeals to the ideas of commedia dell'arte. The latter is genetically connected with street Feasts. Carnival and its characteristic features in Ptushkin's suite are already declared in the names of the first two parts of the cycle («Masks», «Divertissement»). These pieces are related, creating the atmosphere of diversity, fleeting glimpse of Masks - images, their instant sketching.

The names of the first piece - "Masks" - and the second one - "Divertissement" - witness their unity. Divertissement means an addition to the main act. Thus, Ptushkin not only increases the gallery of image-masks in the first part of the cycle but he consolidates the main method by means of 
the structural organization of the whole cycle, because in the following parts of the carnival episodes change continues, though it does not become evident enough thanks to specific features of thematism and the methods of development in the third part.

On the other hand, genre-dancing specific features of intonation development in each of the parts make up the basis of its association with the suite cycles being one of the varieties of a cycle instrumental form.

The character of dance-genre in the cycle "Theater kaleidoscope" to a great extent leans towards the ancient genre of chamber suite with a free sequence of dances. At the same time, the literary programming and definite plot absence keep Ptushkin's suite apart from programming suites of the XIX century (Bizet, Grieg, Tchaikovsky, Rimsky-Korsakov, Musorgsky). "Masks" of musical images differ his work from Shuman' $s^{5}$ suite of "characters" as well as the suites of the $20^{\text {th }}$ century compiled from the music to films.

The first half of the suite (by names of the parts, frequency of changes of thematic material, rhythmical characteristics and so on) mostly announces carnality, relation of the phenomenon in a musical composition with its analogue in other types of art, for example, theatrical coming to the fore.

Dance genre determination as pure musical means creating a carnival atmosphere is concealed behind the name of the first two parts. In the second half of the cycle namely distinctness of dancing genre comes to the fore. The dancing genre in the title does not limit its meaning to a pure musical means creating Kaleidoscope effect. This effect includes thematic homogeneity inside of one part and change of various fragments with transformed dancing theme pattern realizing the principle of alternation. Thus, dance (which is characteristic for ancient camera suite) runs through the entire cycle - in a veiled or open-concrete way. Frequent change of small pieces saves the Kaleidoscope character of carnival.

The mentioned carnival Kaleidoscope features give ground to find in the cycle the signs of some definite type of dramaturgy - that is suite ${ }^{6}$. Numerous scientific definitions of music dramaturgy and the absence of any its universal definition attracts attention to this notion according to the task set in the given article.

Music drama is often correlated with activity and density of the image and structure development. The term "dramaturgy" is often associated with the term "conflict". However, various drama types defined in musicology make it possible to state, that "... in this or other way any musical

\footnotetext{
${ }^{5}$ The change of ancient dancing suite by "character" suites (individualized images) in the Shuman's creative work is analogs to the change of traditional masks comedy by the "character" comedy in theatrical art. It makes it possible to consider the mentioned process to be an objective feature of a corresponding era.

${ }^{6}$ Chernova gives the analysis of other authors' classifications of dramaturgy types: “... the following types of musical drama are defined out: epical, lyrical, dramatic (Sollertinskiy, 1963); one-two-three multi-elements (Bobrovskiy, 1978); narrative and modeling (event developing) (Medushevskiy, 1979). In different works one can come across such names as: classical, romantic, symphonic, opera, cycle, sonata, dialogue, contrast, conflict, concept, neo-epic, plot, assembly, parallel, successive, through, author, performing and so on" (1984, p. 5).
} 
composition is guided by drama principles because the main music formation laws are based exactly on them: theme and key contrasts, goal-oriented development, unity of the whole and so on..." (Chernova, 1984, p. 60). All stated above helps not to limit dramaturgy research to the frames of sharp drama composition with clearly expressed conflict being the source of the development.

We take Skrebkov's definition (1973) as the basis: “... thematic development by means of music language and form formation" (p. 20), because this definition clearly points to two on sides of drama - thematic and structural ones despite the widespread tendency to connect the notion "drama" only the notion "dramatic". The first one includes the development of the composition artistic images, because the "theme" represents imagery (Ruchievskaya, 1977). The second one draws attention to the procedural design of this imagery as a means of its realization.

Study of the cycle genre panorama was necessary because the dance genre comparison of the cycle also determines image-thematic movement-development and its structure, i.e. it forms a type of drama. It is revealed in the succession of the third and the fourth parts - "Waltz" and "Gallop" - thanks to the name of the definite dance genre. The comparison of non-concrete dancing genre of the first two parts and definite lyrics of Waltz serve the same goal to define the third part as a distinctive semantic center in the cycle structure. The third part is included to the Kaleidoscope development only on the level of the whole. But this part falls out of the whole development thanks to its inner characteristics. To ground this statement, according to the chosen definition of dramaturgy, it is necessary to analyze inner thematic movement-development and its process-structure music setting in the suite parts.

The features of suite type drama within the entire cycle are also realized in every part and during every moment of theme intonation development. Thus, the first two parts - "Masks" and "Divertissement" - according to the number of mini-sections with new thematism are also original suites. In the first part there is an introduction and four mini-sections presenting a new mask-image. In the second one there are six mini-sections and also an introduction and a conclusion. In the fourth part (the third part falls out of the general discussion and will be studied separately in connection with its thematic and composition features) there can defined four mini-sections. The episodes of this part have their own peculiarities: greater volumes and general thematic material. It is the material that serves to be the basis of related theme-images, though they are different. The greater duration of mini-sections of the fourth part, objectively compresses in the time of duration with the help of the quick tempo (Presto), given Alla breve and Gallop rhythm energy. Described originality of the fourth suite part does not violate the general carnival flashing, circling, general running due to the mentioned factors.

Suite dramaturgy features also appear in the thematism of these three parts. Themes of each mini-sections are characterized by lapidary, division into short chants. It is in great part determined by characteristic dancing rhythmic-formulas. As a rule, the volume of chants equals half of the measure (which stresses dancing rhythm), but sometime it is restricted by the less fragment of bar. For example, in the part "Masks" - bars 20-26, 28-35; in the "Divertissement" - bars 9-10, 10-11, 11-12, 19-20, 20- 
21, 21-22, 36-37, 37-38, 38-39, 41-42, 43-44, 47-48 and so on; in the "Gallop" - bars 3-4, 4-5, 5-6, 6-7, 7-8 and so on, and also 11-12, 12-13 and so on. In the same part there are examples of the same lapidary chants in the increased quantity Alla breve - the chant is given in the doubled duration: instead of the quarter-note - half-one, instead of the eighth-notes - quarter-one (bars 37-66).

The described lapidary quality of thematism is connected with concentrated characteristics of the mask-image in the Ptushkin's suite. In reality in all the variants of the initial theme the first chant presents the most characteristic features. They remain constant during all the mini-sections in the studied cycle parts.

Lapidarity of thematism, constant and concentrated characteristics of the features create vivid masks-images. A small highlight as a supplement in each case does not change the generalized nature of the themes. For example, in the first image, the inter-bar intonation acts as such, which appears either as a downward fifth (bars 1-2, 2-3 and so on), or as a minor second (bars 3-4, 4-5, 7-8, 8-9). The upbeat eighth accentuation opposing pulsation of quarter notes, introduces rhythmic discordance into the even metrical ripple. It becomes the rhythmic zest of this image. In the second mini-section - a flam in the second or fourth beats of the measure, stresses an unaccented beat by an upward skip and swings the stability of metrical ripple too. In the third mini-section - it is staccato stroke application in the upward intonation skip. In the fourth one - it is a dotted rhythm, intensifying intonation bent for stressed beats and relatively stressed beats of measure. It restored stability of metrical ripple (bars 2836). The other parts of the cycle contain practically the same number of similar examples.

Combination of defined thematic features: lapidary, absence of intonation development, image concentration, catchy characteristics - absolutely corresponds to the principles of a crowded carnival: lively flickering of the masks, fast change of impressions imprint only typical features of images. Carnival mess, fast movement doesn't give any possibility of taking a good look at the masks features and even don't suggest deepening into the image, looking at,-listening to its unique essence. Individual features of each image remain beyond the carnival - this is the specific feature of the suite dramaturgy type.

The summary is common for the analyzed parts of the suite: thematic deployment, thematism peculiarities correspond to the suite type drama of each part. Small inner mini-sections and frequency of their change strengthen the effect of fleeting of appearing and disappearing masks-images. Suite type dramaturgy is used by the author both at the cycle level as a whole and at the scale level of separate parts.

Separate consideration of the thematic movement and its design in the third part of the cycle is justified due to a number of features. First, it is the presence of only two themes, but not several, like in other parts. Secondly, impossibility of kaleidoscopic alternation of mini-sections. Third, it is opposition, contrast of dominating themes. Fourthly, penetration of the whole flesh of the third part from the beginning to the very end by the interaction of both topics.

For the reference, we will take Mazel's (1979) understanding of the theme, who defined it as “... musical thought ... which is distinguished by sufficient structure, adequate concentration, character 
and individuality of music expression usually stressing development" (p. 151). Enumerated features of the theme make it possible to see two themes in the third part: the first one - bars 21-34; the second one - bars 35-50.

The quality of individualization and its function of basis development are particularly important for the study of drama features of the third part. In the first theme the quality of individualization is repeated forth interval creating a sign of barcarolle wiggle and gamma-forming ups without reaching the top. The second theme expresses more individualized character created by the pathetic intonations, skips of melodic sounds at wide intervals of major seventh, of major ninth; abundance of non-chord sounds; many dissonant detentions leading new harmony. The dotted rhythm plays an especially important role in dramatization of this theme character creating emotional tension. Here the dotted rhythm in which the shorter duration (sixteenth) falls on the stressed beat of the measure, and a longer one taken by the skip (eight with a dot) falls on the unstressed one. Described intonation and rhythm dissonances give the second theme dramatic, restless character and they are its individual features.

Individualization, as a rule, is natural lyrical embodiment ${ }^{7}$. In the given case, lyrical beginning is stressed using the Waltz as a genre basis of movement in the third part, Waltz, beeing a symbol of romanticism. In its most essential meaning, romanticism (in its scientific-theoretical and concretehistorical meaning) "... is nothing but inner world of a man, sacred life of his heart... Its sphere - entire inner, hearty life of a man..." (Belinskiy, 1955, p. 145).

Theme special, individual features of the third part create deep, relief characteristics of subjective world of dominating images by means of embodiment of numerous nuances of one mood, sudden their changes, contrasts and so on. Waltz genre adherence to poetic, flexible embodiment of the individual-subjective feelings surely describes it as the sphere of lyrical one.

According to the written above, it is possible to state that the third part contrasts the preceding and the following development in the cycle and composes its lyric center.

However, the peculiarity of the waltz dance genre application introduces new features in the lyrical sphere: the condition of both themes existence exposing opposite images is not a concrete dance - waltz, but its separate and often transformed elements depending on the musical development. This is sooner only a sign of the waltz. That is why, as a genre basis of the movementdevelopment of imagery we should name not the waltz itself but waltz effect. The reason for it is the characteristic rhythmic waltz pattern. In its main form it appears only in the introduction (but not in all the bars) and several times at the very end of the piece under "dying out" of separate thematic phrases. During the whole piece rhythmical waltz formula appears then in the form of the downbeat and detained second one; then in the form of the downbeat and the third beat resting on the second one; then in the form of the downbeat "disperses" into shorter durations and so on. All mentioned

\footnotetext{
${ }^{7}$ In this case, a lyric beginning is used in synonym of the individual utterance.
} 
features hide waltz character - "dropping curtsey" on the downbeat. Mentioned devices permit to speak about a sign of the waltz as genre basis of the development. When realizing an artistic task this approach is right because waltz features are capable of changing. They are necessary for realization of the thematic development depending on the artistic task, in other words depending on the stage of the artistic image formation and on the music events.

Leading themes of the third part oppose each other. Thus, the first theme is lyrical, mild. It dominates only in the first mini-sections (bars 21-34) and later its second element appears only as the completion of the second theme development (bars 47-50, 63-66) or in the form of reminiscence of the initial element of the first theme in the double dominant key (bars 105-112). In general, this theme is presented during the entire process of development like separate intonations going through the music "fabric".

The second theme has more vivid individuality intonation and it is more rhythmical and structural. Intonation individuality is expressed by skips on wide interval (i.e. bars 35-46 and following the text analogs fragments). Skipping intonations in tune composition of the second theme present their characteristic features from the first to the last realization with all drama changes.

Peculiar dotted rhythm representing so-called mirror reflection of accustomed $-\sqrt{.}$ creates special intonation character. Prolonged melodic sound is moved to the second sixteenth of every beat. The character of pathetic, dramatic expression gives the function of "leader" movement, the push function of development.

Thus, in contrast to the dancing genre in other parts of the cycle, the role of the waltz features in the third one is dual. On the one hand, it is an additional characteristic of the lyric beginning, on the other hand, it is the means of expressing dramatic features of the second theme thanks to the usage of signs of these dancing genre.

It is important to note that dramatically waltz features are a uniting rhythmic basis and as well as for further dialogue interaction of the leading themes, and for transformation of theme-images during dramatization of music events. Thus, waltz features become the basis of the first theme transformation from the structural unity to the gradual disintegration into separate elements, from dearly expressed transparently-light lyrics - to overwhelmingly sad colored ones. For the second theme waltz features become the basis for the gradual dramatization and the climax of the development.

Waltz plastic is also the foundation for drama interaction of themes transforming into underdetermination, intergrowth. Closer to the end, the composition result is presented by a short quasinew three-measure phrase, where the features of both themes mix up. Deformation of the initial theme-images reflects dramatism of music events. By its character three-measure phrase is close to the first theme but in the intonation aspect it has got intervals from the second theme: minor sixth and minor seventh. They are represented in the textual expression of the first theme, but in the keys contrasting initial in $\mathrm{C}$ minor. They are $\mathrm{C}$ sharp minor and $\mathrm{A}$ flat minor (the third level of relation, bars 
128-131), B flat minor (the second level of relation) and $\mathrm{F}$ minor (bars 131-135). The harmonic shifts are particularly often characteristic for final mini-section of the third part (from measure 128 to the end), at the final stage of theme-images interaction.

General line of theme transformation, changes of the character of their interaction can be traced from the dialogue through the gradual interpenetration till the disappearance of the lyrical theme. It is obvious that changes of the dominating themes are the musical events ${ }^{8}$; and targeting of their development reflects the "event", lyric-dramatic logics of the formation of the artistic value of the third part. This combination of dramatism and lyric makes the third part to be the lyric-drama center of the cycle.

Thus, the above studied problems permit to suggest drama heterogeneity of the cycle. Two types of the drama are obvious - suite, kaleidoscopic and lyric-dramatic.

The application of lyric-dramatic type of drama in the third part makes logical accent on the organization of the suite as a whole. This accent is created by new thematism realizing unexpected images within kaleidoscopic rounds and its following development. In the sphere of form formation application of lyrical-dramatic and event drama in the third part leads to the change of its function ${ }^{9}$ in the suite. The function of the unit in the chain transforms into the function of the lyric-dramatic center of the suite.

The change of the drama type connected with it function change of the third part is reflected in the structural organization of the whole. Process of distinguishing the third part in the general kaleidoscope movement creates ternary form in scale of the form of the whole. The forth part as final one of the suite creates a specific recapitulation by the resumption of the suite development, return of kaleidoscopic narrations.

Forming of the separate parts into ternary form allows to get over principal "openness" of instrumental suite as the genre with the help of the logic image-thematic development, which “... permits to build up the producer's plan of performance in accordance with composes concept ..." (Nazaykinsky, 1982, p. 16). Nazaykinsky (1982) understands the producer's plan as a composition work of the author, which lies in the correlation of the suite (or variation) principal with any other organizing principal - the form of the background. This helps to give quality curtain to a number of pieces, unconnected by "through", "plot" drama and to solve the problem of the artistic wholeness of the composition.

\footnotetext{
${ }^{8}$ Taking into the account Medushevsky's statements, literary criticism categories "events" and "actions" exposing the characters, can be used when studying music drama (Medushevsky, 1979)

9 "Drama functions - generalization of numerous varieties which are beyond of the account of all types of expression... This generalization appears in every separate case on the basis of the realized artistic idea in the given musical composition. Fundamental parameters in the process of generalization of drama functions run parallel to the main parameters of the psychological types. The latter corresponds to the system of the generalization types of imagery expressiveness" (Bobrovskiy, 1978, p. 60).
} 
In the research of drama peculiarities of the Ptushkin's suite "Theatre Kaleidoscope", ternary form, including the Skrebkov's (1973) determination of the components of dramaturgy, permits to see "... not just a composition in general, but a temporary whole subordinated to art wholeness organized according to the principles of music arrangement" (Nazaykinsky, 1982, p. 18).

In the given case, the third part having the function of lyrical-dramatic center in the cycle is one of the ways of creating a simple ternary form in the processing-structural formation of the suite form. And the last one, as a form of the background, gives the architectonic harmony and completeness of the Ptushkin's suite "Theatre Kaleidoscope".

Novelty of the research work includes the first test of the analysis of one of the piano compositions of Ptushkin. The novelty is: the definition of genre-historical ties of the Ptushkin's suite with the ancient chamber suite and with commedia dell'arte; exposition of the meaning of the suite type dramaturgy as the main organizing processing-structural principle of the whole cycle; basing the application of the "event" lyric-dramatic type of drama in the third part; definition of the influence of the third part inner dramaturgy peculiarities on its function in the cycle; exposing the ternary form in the arrangement of the suite artistic unity.

\section{Conclusions}

All written above allows us to draw the following conclusions. The most important and initial dramatic feature of Ptushkin's piano suite is the use of two types of dramaturgy in organizing her artistic whole - suite and lyric-dramatic. This allows us to compare directly opposing spheres of imagery - festivity, fun commotion and deep drama. For the performing organization of suite artistic whole, the sharpening of the inherent opposition remains variable.

Suite type dramaturgy is leading in the given suite. It is used in three parts of the suite - the first, second, and fourth. The lyric-dramatic type of drama dominates only in the third part. Both types of dramaturgy are realized on the basis of everyday dance genre. Therefore, to a great extent means of the embodiment of this confrontation is the transformation of dance-rhythmic formulas.

The author's "game" with dance formulas is especially significant for the third part. It (the game, i.e. variation) becomes the basis of the lyric-dramatic type of dramaturgy in the third part. The mixture of the two types of drama is not only a means of figuratively thematic development of the artistic whole for the author, but also a structurally organizing principle. It is the use of the lyricdramatic type of dramaturgy that makes it possible to distinguish the third part of the cycle as the lyricdramatic semantic center of the artistic whole. A separate semantic climax of the cycle is the organizing structural principle of the whole. As a result, the three-partness of the suite as a whole is formed. This creates the quality of completeness of the suite artistic whole that is the goal of both the composer and the performer. 


\section{References}

Belinsky, V. G. (1955). Articles above Pushkin. Article second. V. 7. Articles and reviews (1843-1845). V. S. Spiridonov (comments) \& D. D. Blagoy (ed.). In Complete works: in 13 volumes. (pp. 132-222). Moscow: AN SSSR Publishing House.

Bobina, I. (2001). Some lines of piano style by V. M. Ptushkin. Musical and theatrical art of Ukraine by the eyes of young art critics, 14-18.

Bobrovsky, V. (1971). To the question of dramaturgy of musical forms. In Theoretical problems of music forms and styles: collection of reasons (pp. 28-64). Moscow: Music.

Bobrovsky, V. (1978). The Functional bases of music forms. Moscow: Music.

Chernova, T. (1984). Dramaturgy in the instrumental music. Moscow: Music.

Dyatlov, D. A. (2014). Elements, relationships and connections in piano interpretation. News of the Samara Scientific Center of RAS. V.18, 2(3), 737-741.

Inutochkina, N. (1996). Performance features of the vocal cycle "Funny Pictures" by V. Ptushkin. Problems of interaction between arts, pedagogy and the theory and practice of education, 3, 73-75.

Kreg, E. G. (1988). Actor and super marionette. A. G. Obraztsov, Yu. G. Fridshteyn (ed.), A. G. Obraztsov (introd. article), Yu. G. Fridshteyn (comments), and V. V. Voronin \& others (transl. from English). Flashbacks, articles, letters (pp. 212-233). Moscow: Art.

Livanova, T. (1980). Vocal forms and the large composition problem. In Y. S. Bach's music dramaturgy and its historical connections. P. 2. Moscow: Music.

Mazel, L. (1979). Structure of music works: trained. (2nd ed., process. and compl.). Moscow: Music.

Medushevsky, V. V. (1979). About musical universals. In S. S. Skrebkov. Articles and flashbacks (pp. 176-212). Moscow: Soviet Composer.

Nazaikinskii, E. V. (1982). The logic of musical composition. Moscow: Music.

Ruchevskaya, E. (1977). Functions of music theme. Leningrad: Music.

Skrebkov, S. S. (1973). Art principles of music styles. Moscow: Music.

Sollertinsky, I. (1963). Historical types of symphonic dramaturgy. In Historical etudes (pp. 335-346). Leningrad: Musgiz.

Vartanov, S. Ya. (2012). B. Yavorsky and conception' range of problems in the system of piano interpretation (associative image of the "Ladder" in the Prelude and Fugue E-dur by I. S. Bach, WTP, V. 2). Vestnik of SSTU, 1, 134-142. 